\section{Resposta à aids no Brasil: contribuições dos movimentos sociais e da reforma sanitária}

\author{
Alexandre Grangeiro, ${ }^{1}$ \\ Lindinalva Laurindo da Silva ${ }^{2}$ \\ e Paulo Roberto Teixeira ${ }^{3}$
}

Como citar: Grangeiro A, Laurindo da Silva L, Teixeira PR. Resposta à aids no Brasil: contribuições dos movimentos sociais e da reforma sanitária. Rev Panam Salud Publica. 2009;26(1): 87-94.

Palavras-chave: síndrome de imunodeficiência adquirida, artigo histórico, política de saúde, organizações não governamentais, reforma dos serviços de saúde.

\footnotetext{
Universidade de São Paulo, Departamento de Medicina Preventiva. Correspondência: Avenida Dr. Arnaldo 455, $2^{\circ}$ andar, CEP 01246-903, São Paulo, SP, Brasil. Fone: +55-11-3061.7076; e-mail: ale.grangeiro@ gmail.com

2 Association Nationale des Généralistes pour la Recherche et l'Étude sur l'Hépatopathie Chronique (ANGREHC). E-mail: laurindo.da. silva@ dalva.org

Secretaria de Estado da Saúde de São Paulo, Centro de Referência e Treinamento de Doenças Sexualmente Transmissíveis e AIDS, São Paulo (SP), Brasil. E-mail: pteixeira@saude.sp.gov.br
}

Desde o surgimento da aids no Brasil, em 1983, mais de 205 mil mortes e 506 mil casos foram registrados no país $(1,2)$. No mundo, somente no ano de 2007, foram 2,7 milhões de novas infecções e 2 milhões de mortes, a maior parte em países de média e baixa renda (3). Para traçar um paralelo, buscando situações semelhantes, com um número tão grande de vítimas, é preciso voltar a outras épocas - como a idade média, quando a peste negra dizimou cerca de 20 milhões de vidas, o que representava uma parcela expressiva da população europeia, ou o início do século XX, quando a gripe espanhola matou entre 20 e 50 milhões de pessoas em todo o mundo $(4,5)$.

Ao final da década de 1980, os indicadores epidemiológicos da aids no Brasil eram semelhantes aos de muitos países da África Austral (6), onde, atualmente, a epidemia apresenta contornos alarmantes (3). À época, análises apontavam para o risco de a epidemia se generalizar na população brasileira e provocar expressivo impacto na economia e na saúde. Esse temor era justificado pela velocidade de crescimento da doença no Brasil, um país marcado pela diversidade social, econômica e cultural, pelo surgimento de um expressivo número de novos casos entre mulheres e homens heterossexuais e pela manutenção de incidências altas em grupos sociais mais vulneráveis $(7,8)$.

Passadas pouco mais de 2 décadas, não se concretizou o cenário previsto pelo Banco Mundial no início dos anos 1990, de que 1,2 milhão de brasileiros estariam infectados pelo HIV no ano 2000. As taxas de mortalidade por aids caíram em média $50 \%$, a sobrevida das pessoas vivendo com HIV aumentou pelo menos 5 vezes e a prevalência da infecção na população de 15 a 49 anos permanece estável, em patamar reduzido. Estimativas oficiais indicam a existência de 600 mil pessoas vivendo com HIV no país, o que significa uma prevalência de $0,6 \%$ na população adulta $(1,9)$.

Muitos fatores contribuíram para o alcance desses resultados. Dentre eles, julgamos como os mais relevantes a reforma sanitária, o contexto sociocultural dos anos 1970 e 1980 e a estratégia adotada pelo Brasil no cenário internacional, que serão analisados neste artigo.

O movimento da reforma sanitária, que cresceu no início da década de 1980, diante do intenso processo de redemocratização política e do surgimento dos primeiros casos de aids, se constituiu no principal arcabouço da política de aids desenvolvida em âmbito governamental, contribuindo para fundamentar seus princípios e diretrizes. O contexto sociocultural dos anos 1970 e 1980, por sua vez, foi marcado pela conquista de liberdades individuais e pelo avanço no reconhecimento dos direitos de populações socialmente 
marginalizadas, como mulheres, homossexuais e negros. É este ativismo político que permitiu a imediata reação de movimentos sociais frente à aids, tanto no plano da atenção à saúde como na prevenção e no combate às situações de discriminação dirigidas aos grupos mais afetados e às pessoas vivendo com HIV e aids. Esse movimento, do qual participaram, entre outros, igrejas, setor privado, comunidade científica e organizações não governamentais (ONGs), além de impulsionar as políticas públicas, permitiu uma organização social fundada na solidariedade, um conceito compreendido, no âmbito do movimento social, como uma ação coletiva cuja finalidade é preservar a cidadania dos doentes e dos grupos mais atingidos. Quanto à estratégia internacional adotada pelo Brasil, além de influir no contexto global, possibilitou o fortalecimento da resposta à epidemia da aids dentro do próprio país.

Para a sistematização dessa discussão, foram utilizadas fontes documentais e bibliográficas e dados que resultam da pesquisa "Aids: história de uma epidemia", realizada entre 2002 e 2005 (pelos autores LLS e PAT) em todos os estados da federação, com apoio do Ministério da Saúde do Brasil.

\section{Os princípios de universalidade, equidade e integralidade da resposta brasileira à aids: contribuições do movimento de reforma sanitária}

O movimento pela reforma sanitária surgiu entre as décadas de 1950 e 1960, tendo como referência as universidades e as experiências das secretarias de saúde, especialmente nos estados das regiões Sul e Sudeste do país. Nesse período, ocorreu o fortalecimento dos departamentos de medicina preventiva, da produção científica e dos debates que enfatizam os aspectos sociais e coletivos nos processos de saúde. Ao mesmo tempo, as secretarias de saúde iniciaram processos de reforma, priorizando a descentralização, a ampliação da cobertura das ações e o aprimoramento da gestão e das ações de promoção (10). Ganhou destaque, pelo pioneirismo, o processo conduzido no âmbito da Secretaria de Estado da Saúde de São Paulo, ocorrido ao final da década 1960 (11).

Paradoxalmente, esse movimento ganhou dimensões nacionais no auge da ditadura militar, em um período em que se aprofundavam as discussões sobre os históricos problemas da saúde pública no Brasil entre eles a baixa cobertura das ações assistenciais, que abrangiam, fundamentalmente, os indivíduos com vínculo empregatício; a existência de múltiplos sistemas de saúde que operavam nas esferas federal, estadual e municipal; os elevados gastos públicos com saúde diante da crescente participação do setor privado na prestação de serviço; e a falta de articulação entre os níveis de atenção à saúde e as ações curativas e preventivas (12-14).

Nesse cenário, na década de 1970, foram levados a cabo diversos arranjos, que visavam a criar ou fortalecer órgãos de gestão e de administração centralizados para prover medidas sanitárias e assistência indi- vidual. Datam desse período o Sistema Nacional de Saúde (1975), a Secretaria Nacional de Ações Básicas de Saúde (1976) e o Sistema Nacional de Previdência Social (1977), que incorporou o Instituto Nacional de Assistência Médica da Previdência Social (INAMPS) $(10,13,14)$.

O aprofundamento dos novos arranjos institucionais, entretanto, veio a ocorrer a partir de meados dos anos 1980, com o esgotamento do regime militar, o fortalecimento do processo de redemocratização política e a reorganização de movimentos sociais e culturais. Em 1980, foi criada a Comissão Interministerial de Planejamento, que passou a articular e a planejar as atividades desenvolvidas pelos Ministérios da Saúde e Previdência Social. Em 1982, foram instituídas as Ações Integradas de Saúde (AIS), que ampliaram a cobertura das ações de saúde, integraram as atividades de assistência preventiva e curativa e criaram as instâncias colegiadas de gestão do sistema de saúde nos três níveis de governo, já prevendo a participação de movimentos sociais $(13,14)$. Esse foi o início do processo de institucionalização do comando único do sistema de saúde em cada esfera de governo, da organização da atenção à saúde com base na integralidade e do controle social das políticas de saúde.

Contudo, a hegemonia do movimento sanitário na organização do sistema de saúde veio com a $8^{\circ}$ Conferência Nacional de Saúde, ocorrida em 1986, e com a criação do Sistema Único de Saúde (SUS) na nova constituição federal promulgada em 1988. Com a nova constituição, consolidaram-se definitivamente a noção de saúde como um direito a ser assegurado pelo Estado e a organização do sistema de saúde fundamentado nos princípios de universalidade, equidade, integralidade e controle social (10). Essas foram as características que influenciaram o desenho de programas e estratégias de saúde na década de 1980, período em que surgiram os primeiros casos de aids no Brasil, notificados na Cidade de São Paulo em 1983. Também é de 1983 a primeira resposta governamental à epidemia, com a criação do Programa de Aids da Secretaria de Estado da Saúde $(15,16)$.

A organização do Programa de Aids de São Paulo foi uma resposta às inquietações de representantes da comunidade homossexual. Em junho de 1983, esse grupo, preocupado com o surgimento da doença no Brasil e com as informações provenientes dos Estados Unidos, que indicavam a possibilidade do crescimento acelerado do número de novos casos, demandou ações concretas das autoridades de saúde para minimizar os efeitos desse novo agravo $(15,16)$.

A estrutura do novo programa articulou quatro estratégias: serviços de referência assistencial e laboratorial, vigilância epidemiológica, informação e educação à população e mobilização e participação social. Entre as diretrizes, se destacam o combate à discriminação, a garantia do acesso universal ao tratamento e a promoção da equidade para os grupos sociais mais afetados no acesso aos recursos disponíveis.

É importante, ainda, ressaltar o papel da política para o controle da hanseníase na definição das primei- 
ras estratégias de controle da epidemia de aids. O programa de aids, em São Paulo, foi implantado na Divisão de Dermatologia Sanitária e Hansenologia do Instituto de Saúde (15), estrutura sucedânea do Departamento de Profilaxia da Lepra, responsável durante várias décadas pelas ações de controle da doença no Estado. Nos anos anteriores, essa política havia passado por profundas alterações, com o término do isolamento compulsório de pacientes, a incorporação dos determinantes sociais nas ações de promoção à saúde e a ênfase nas estratégias de redução do estigma, o que motivou a alteração do nome oficial da lepra para hanseníase (17).

Foi a mesma equipe da Divisão de Dermatologia e Hansenologia que se responsabilizou pela organização do programa de aids e pela oferta dos serviços assistenciais, de vigilância epidemiológica e de prevenção. $\mathrm{O}$ ambulatório de atendimento de portadores de hanseníase, formado por equipe multidisciplinar, tornou-se o primeiro serviço de referência no estado para pacientes com aids e de informação sobre a doença à população por meio de uma linha telefônica específica (disque-aids).

A estrutura organizativa do programa paulista (com a influência das diretrizes estabelecidas no âmbito da reforma sanitária e da política de controle da hanseníase) e a forte participação de segmentos sociais mais afetados passaram a ser referência e a influenciar a atuação de outros estados e do governo federal. No Rio Grande do Sul, por exemplo, as ações contra a aids passaram a ser estruturadas a partir de dezembro de 1983, quando foram notificados dois casos. Naquele estado, assim como em São Paulo, as primeiras ações foram atribuídas ao Serviço de Dermatologia Sanitária. No Estado do Rio de Janeiro, embora as atividades estaduais tenham se institucionalizado em 1989, as primeiras respostas ocorreram desde 1984, a partir da atuação de um grupo de médicos e mais tarde com o engajamento de representantes da sociedade civil.

Em cidades do Nordeste, como Natal (Estado do Rio Grande do Norte), Recife (Estado de Pernambuco) e Salvador (Estado da Bahia), também a aids começou a ser identificada na primeira metade da década de 1980. Apesar dessas notificações e do envolvimento de médicos no tratamento da doença, os programas de controle da aids nessa região foram impulsionados a partir de 1987, com a forte indução do Programa Nacional de Aids, que, criado em 1986, também no âmbito da área de Dermatologia Sanitária do Ministério da Saúde, fortaleceu as equipes locais com recursos técnicos e financeiros.

A partir da criação do Programa Nacional, implantou-se uma verdadeira rede de interlocução entre profissionais e instituições, que trouxe como consequência a nacionalização da resposta à epidemia e a adoção de diretrizes que fundamentaram as primeiras ações de enfretamento da epidemia em todo o país. Essa organicidade fortaleceu-se a partir de 1994 com recursos provenientes de um acordo de empréstimo com o Banco Mundial, que permitiu o financiamento de projetos de prevenção e assistência governamentais e não governamentais, a incorporação de novas tecnologias e a ampliação da produção de conhecimento sobre a doença (18). O acordo com o Banco Mundial e a consequente ampliação das ações de controle inauguraram uma nova fase da resposta brasileira à aids, que, entretanto, não será objeto de análise neste artigo.

\section{Ativismo em aids: a contribuição dos movimentos sociais de defesa de identidades e direitos}

Um dos principais consensos na literatura disponível é o importante papel que a sociedade civil desempenhou na construção da resposta à epidemia de aids $(6,15,18,19)$, seja pela contribuição da ação em comunidade, com a finalidade de reduzir a prevalência e a mortalidade por aids, seja pela busca de uma caracterização das políticas de saúde a partir do ativismo e do controle social. Nesta parte do trabalho, discutiremos a construção da resposta da sociedade brasileira a partir do ativismo dos movimentos sociais, que, fundamentados em uma matriz de solidariedade, contribuíram para garantir os direitos dos grupos mais atingidos e para organizar políticas públicas de enfrentamento da epidemia.

Os anos 1960 e 1970 foram marcados pela contestação dos valores tradicionais e pela reivindicação das liberdades individuais. Foram anos de conquistas relacionadas às liberdades sexuais e à quebra de tabus, como, por exemplo, o questionamento do casamento como condição de união entre casais. Esse movimento de contestação dos valores então vigentes se iniciou nos Estados Unidos e nos países da Europa Ocidental e logo assumiu proporções consideráveis na sociedade brasileira, principalmente entre a classe média urbana e intelectual (20).

Nesse contexto, a identidade homossexual ganhou visibilidade em algumas cidades do Brasil, como São Paulo, Rio de Janeiro e Salvador, com o florescimento de locais de interação social e de um intenso movimento político, que, fundamentado no reconhecimento de diferenças, visou a romper os limites marginais do grupo, denunciar situações de violência e afirmar e defender direitos de pessoas com identidade homossexual (20). Destacaram-se, nesse período, a organização do Jornal Lampião da Esquina, editado no Rio de Janeiro por um grupo de intelectuais, e o Grupo Somos, criado em São Paulo e posteriormente no Rio de Janeiro $(20,21)$.

No início dos anos 1980, o Grupo Somos sofreu um processo de desarticulação, provocando cisões e enfraquecimento no movimento homossexual que se estruturava. Na base da desarticulação estavam divergências sobre as estratégias políticas a serem adotadas. De um lado, havia os que defendiam a manutenção de uma prática política autônoma, com prioridade das ações para garantir a visibilidade de uma identidade homossexual; do outro, havia aqueles que preconizavam o engajamento do movimento nos processos de abertura política e de contestação da ditadura militar $(20,21)$. 
Apesar dessa desarticulação, surgiram, nesse período, como dissidência do Grupo Somos do Rio de Janeiro e de São Paulo, os grupos Outra Coisa, em São Paulo, e o Auê, no Rio de Janeiro. Nasce também o Grupo Gay da Bahia (GGB), que desempenhou um papel importante na luta pela afirmação da identidade homossexual no período que se seguiu.

$\mathrm{O}$ registro dos primeiros casos de aids no país, em 1983, teve, também, um impacto no movimento homossexual, intensificando o seu enfraquecimento e levando uma parte dos ativistas a se articular em torno da luta contra a aids. Esse movimento se constituiu em um dos principais pilares da resposta à epidemia de aids no país $(15,18,22)$. Nos anos seguintes, foi difícil distinguir a militância do movimento homossexual da militância do movimento de luta contra a aids.

Desde o início de 1983, o grupo Outra Coisa Ação Homossexualista tomou a iniciativa de editar uma apostila com informações sobre a aids, pregando a solidariedade incondicional aos doentes. Esse material foi distribuído em locais públicos e de encontro homossexual. A partir de então, grupos como o GGB se mobilizaram e, de maneira pioneira, passaram a divulgar informações sobre a doença e em defesa dos direitos dos homossexuais $(21,22)$.

Além da intensa implicação da comunidade homossexual na formulação de políticas de combate à epidemia, a participação e o envolvimento de homossexuais na resposta à aids ocorreu também pelo plano individual (23), que permitiu criar uma rede de solidariedade e de apoio ao expressivo número de indivíduos da comunidade que adoeciam. Esse fato é evidenciado na medida em que, para muitos indivíduos afetados diretamente, a comunidade homossexual foi a responsável por viabilizar o tratamento e a ajuda material e afetiva necessários para a convivência com a doença, uma situação que era agravada pela morte dos parceiros e pela falta de um arcabouço jurídico que permitisse o reconhecimento dos direitos à aposentadoria e aos bens provenientes da relação de conjugalidade.

Em torno das primeiras respostas da sociedade civil surgiu, em São Paulo, o Grupo de Apoio e de Prevenção à Aids (GAPA), primeira $\mathrm{ONG}$ de aids a atuar no Brasil. Fundado em 1985, o GAPA era composto em sua maioria por homossexuais, profissionais de saúde, doentes de aids e seus familiares. A partir dessa data, começaram a surgir, em diversos estados, grupos sociais com o objetivo de desenvolver atividades de intervenção na comunidade, produzir conhecimentos, defender direitos de grupos mais atingidos pela epidemia e realizar o controle social das políticas de saúde (24).

No Rio de Janeiro, o envolvimento da sociedade civil na luta contra a aids iniciou-se também em 1985, quando os homossexuais, ainda que timidamente, passaram a acolher e facilitar as primeiras ações preventivas desenvolvidas pela secretaria de saúde daquele estado. Essas ações foram definitivamente impulsionadas, no final de 1986, pela criação do GAPA-Rio e da Associação Interdisciplinar de Aids (ABIA). Formada por representantes do mundo médico, intelectual, político e artístico, a ABIA teve grande destaque entre as
ONG-aids por suas contribuições no plano político e de produção do conhecimento, entre as quais se destacam o ativismo para uma nova regulamentação do uso do sangue, a organização de instituições não governamentais em rede e a elaboração de propostas preventivas inovadoras $(18,24,25)$.

Os hemofílicos, também fortemente atingidos pela aids nos anos 1980, foram especialmente atuantes em São Paulo (16) e no Rio de Janeiro (25). O movimento em torno da causa dos hemofílicos teve atuação decisiva na proibição da comercialização do sangue no Brasil e na instituição de uma política pública de segurança hemoterápica. Merece também destaque a organização (embora incipiente) de profissionais do sexo, que tiveram, a partir de 1985, uma importante atuação no Rio de Janeiro, com a criação, no âmbito do Instituto de Estudos da Religião (ISER), do Programa de Prostituição e Cidadania (24). Esse programa foi o precursor da Rede Brasileira dos Profissionais do Sexo.

\section{A solidariedade e o direito à vida: novos atores em cena}

A partir de 1983, a aids se transformou em notícia quase cotidiana na grande imprensa e também na imprensa sensacionalista. Algumas dessas matérias semearam pânico na população e cristalizaram imagens moralistas e discriminatórias que pouco correspondiam ao perfil da epidemia que se iniciava $(26,27)$. Essas notícias foram os primeiros contatos que a sociedade brasileira teve com a aids e contribuíram para reforçar a imagem do doente a partir da morte, do preconceito associado a grupos sociais e do sofrimento dos pacientes. Não era incomum a representação de doentes restritos a camas de hospitais, em estado de fragilidade física e em situação sugestiva de morte iminente $(19,22)$. Associado a essa representação, o termo "aidético" passou a ser amplamente utilizado, simbolizando a forma pela qual a sociedade reconhecia a doença e o doente.

Como resposta a essa situação houve uma intensa mobilização da sociedade civil, que se estruturou em dois eixos: o do ativismo político, que reivindicava os direitos dos pacientes, e o da solidariedade, que buscava redefinir os princípios pelos quais a sociedade abordava as pessoas infectadas pelo vírus. Surgiram as casas de apoio, uma forma de organização comunitária para abrigar pessoas sem condições materiais e de moradia, viabilizando o tratamento e a assistência médica. A primeira delas, ainda no início dos anos 1980, foi organizada em São Paulo pela travesti Brenda Lee e tinha por objetivo principal acolher travestis com aids em situação de precariedade social, apoiando o tratamento desses doentes. A partir do final dos anos 1980, outras casas de apoio foram organizadas por segmentos da igreja ou por iniciativas individuais $(19,24)$. Entre os anos 1980 e 1990, essas casas cumpriram um papel importante, permitindo a desinternação e a reinserção social de centenas de pacientes.

Posteriormente à criação das primeiras casas de apoio, com objetivos diferentes, surgiram os grupos de 
autoajuda ou de ajuda mútua, que pretendiam criar uma rede de interação social de pessoas infectadas pelo vírus, facilitando o aprendizado e a convivência com a doença e, quando necessário, o apoio material e social. Entretanto, foi somente ao final dos anos 1980, como resultado do ativismo de pessoas infectadas que reclamavam por cidadania e pelo direito à vida (23, 28-30), que começaram a ser modificadas as representações do doente circunscrito à sua doença e a ser desconstruídas as associações entre aids, morte e exclusão social.

Nesse contexto, em contraposição à representação engendrada no nome aidético, o termo soropositivo começou a ser amplamente utilizado pelos órgãos de saúde e pelas ONGs como forma de identificar as pessoas atingidas pela infecção. Esse termo tem sua origem nos laudos de exames laboratoriais de diagnóstico da infecção pelo HIV e foi utilizado como forma de demarcar a diferença entre indivíduos infectados, que não apresentavam limitações sociais e produtivas, e os que haviam desenvolvido a doença, que passa a ser gradativamente compreendida como uma enfermidade crônica, minimizando o estigma da morte e da fatalidade.

Embora essa nova representação da doença e do doente tenha trazido avanços, não foi suficiente para uma ruptura mais significativa do doente circunscrito à dimensão biológica da doença. Essa inflexão ocorreu de fato com o fortalecimento do ativismo e a criação de grupos de pessoas infectadas pelo HIV, e tem como um de seus marcos o lançamento, por Herbert Daniel, de um movimento de (des)construção da aids como morte civil. Para Daniel (29), o preconceito e o silêncio em torno da doença e do doente impunham às pessoas com aids uma morte em vida, subtraindo qualquer direito ou possibilidade de convivência afetiva e social. Para se contrapor à morte civil, o autor propôs o conceito de viver com HIV/aids, através da solidariedade e do ativismo político $(28,29)$. Cumpriram um papel destacado nesse movimento, pelo pioneirismo e posicionamento político, o Grupo pela Vidda, fundado por Daniel em 1989 no Rio de Janeiro, e o Grupo de Incentivo à Vida (GIV), fundado em 1990 em São Paulo por Jose Roberto Peruzzi $(25,28,31)$.

A partir daí, o movimento social passou a reivindicar a não negação da doença e do doente, questionando a aids como elemento de exclusão e de morte civil. Passou a ser construída uma identidade social do doente calcada na ideia de cidadania e de direito à vida. Pela primeira vez, o nome utilizado para designar as pessoas atingidas diretamente pela doença não guardava correspondência com termos biomédicos, como aidético e soropositivo, restringindo-se simplesmente ao fato e à especificidade do "viver com HIV e aids". Essa identidade permitiu às "pessoas vivendo com HIV" influenciar de forma decisiva a formulação e a manutenção de políticas públicas para aids (23).

O movimento contra a exclusão das pessoas com aids ganhou novos contornos a partir de 1996, com o surgimento da terapia antirretroviral combinada, que mudou significativamente o perfil da epidemia, as representações acerca da doença e, sobretudo, as perspectivas das pessoas vivendo com HIV. Como consequência do surgimento de medicamentos mais eficazes, observou-se a redução da mortalidade, o aumento da sobrevida e a reinserção social de pessoas vivendo com HIV, contribuindo assim para amenizar as situações de preconceito e a associação da doença com a fatalidade. $\mathrm{O}$ alto custo dos medicamentos tornou-se o principal fator de mobilização da sociedade civil, enquanto que o acesso aos antirretrovirais tornou-se uma das principais prioridades de saúde do país $(32,33)$.

Com a vinculação do tema da propriedade intelectual ao tema do acesso ao tratamento, e com a necessidade de se estabelecer vínculos de solidariedade entre países, a atuação internacional passou a ser um dos pilares de sustentabilidade e legitimidade da política brasileira de aids dentro do próprio país.

\section{A atuação do Brasil na esfera internacional}

A participação brasileira na mobilização da comunidade internacional para enfrentar a epidemia de aids e a atuação de organismos internacionais se iniciaram na década de 1980, quando, no âmbito das Américas, a Organização Pan-Americana da Saúde (OPAS) promovia reuniões para atualização da situação epidemiológica e definição de estratégias regionais de enfrentamento da epidemia.

Desde então, o Brasil tornou-se um importante ator no cenário internacional, defendendo as posições que fundamentam a resposta nacional nas áreas de prevenção, assistência e defesa dos direitos humanos (33). O reconhecimento internacional da resposta brasileira à epidemia ocorreu especialmente quando o país implantou o programa de acesso universal aos medicamentos antirretrovirais.

A atuação do Brasil nesse cenário teve duas motivações: obter acordos que viabilizassem a sustentabilidade financeira da distribuição universal dos medicamentos no país e a adoção de uma estratégia internacional para ampliar o acesso em países de baixa e média renda. A primeira motivação decorreu da necessidade de reduzir os preços de medicamentos pagos pelo SUS, por meio da produção nacional de genéricos e da obtenção de preços justos. A atuação brasileira se deu especialmente no contexto da Organização Mundial do Comércio (OMC) e das Nações Unidas (UN), buscando, a partir do debate sobre aspectos dos direitos de propriedade intelectual que dizem respeito ao comércio (trade-related aspects of intellectual property rights, TRIPS), entendimentos que reconhecessem a precedência da saúde em relação ao comércio (33). Entre os diversos acordos obtidos, três merecem destaque.

O primeiro refere-se à adoção da resolução proposta pelo Brasil na Comissão de Direitos Humanos das Nações Unidas, que declara os medicamentos antirretrovirais um direito fundamental do cidadão. A resolução foi aprovada por todos os países membros, com exceção dos Estados Unidos, que se abstiveram, em abril de 2001. 
O segundo evento que merece destaque foi a retirada da queixa feita pelos Estados Unidos contra o Brasil junto à OMC em função de a legislação brasileira permitir a licença compulsória de objetos patenteados não produzidos nacionalmente. A retirada da queixa ocorreu sob forte pressão internacional e às vésperas da Seção Especial da Assembleia das Nações Unidas sobre Aids (UNGASS), em junho de 2001. À época, como elemento de defesa, o Ministério da Saúde veiculou em jornais americanos propagandas que reforçavam os princípios humanitários da política de aids do Brasil.

O terceiro destaque foi a Declaração da Assembleia Geral da OMC sobre propriedade intelectual e saúde em dezembro de 2001. Essa Declaração, tida como um marco na interpretação de TRIPS, reconhece a prioridade da saúde em relação ao comércio e o direito dos países de promover a produção nacional de medicamentos ou de importar genéricos para garantir os programas de saúde pública.

A segunda motivação para a atuação brasileira no cenário internacional, a de contribuir para que países de baixa e média renda ampliassem suas políticas de controle da epidemia e de acesso a medicamentos, se explicava pelo fato de que, no início dos anos 2000, a imensa maioria das 6 milhões de pessoas que necessitavam de medicamentos antirretrovirais não tinha acesso a eles (34). A atuação brasileira, nesse sentido, foi direcionada para influir na agenda dos organismos internacionais, especialmente da Organização Mundial da Saúde (OMS) e do Programa Conjunto das Nações Unidas para Aids (UNAIDS). O país teve uma contribuição importante no estabelecimento de um conjunto de ações que possibilitou uma atuação mais efetiva desses órgãos e que se materializou com a implantação, em 2003, da estratégia " 3 by 5 " da OMS e do UNAIDS, que tinha por objetivo promover o acesso de 3 milhões de pessoas aos medicamentos antirretrovirais até o final de 2005. Essa iniciativa representou uma inflexão na agenda internacional, consagrando o princípio de que o acesso aos antirretrovirais em países de baixa e média renda constituía uma intervenção essencial no âmbito da saúde pública. Uma avaliação independente, conduzida em 2006, demonstrou que, apesar de a meta não ter sido alcançada no prazo estabelecido, a iniciativa propiciou um expressivo aumento no número de pessoas utilizando antirretrovirais, na ordem de 2,3 vezes, a adoção de normas e guias simplificadas para o tratamento de pessoas com HIV em países com sistemas de saúde frágeis e a mobilização de governos, instituições e recursos com a finalidade de garantir a disponibilidade dos medicamentos e dar suporte aos países para a organização de programas de acesso (35). Cerca de 3 milhões de pessoas estavam recebendo tratamento antirretroviral ao final de 2007, o que representa um aumento de 7,5 vezes em 4 anos (34).

A atuação do Brasil nas instâncias internacionais contribuiu, também, para consolidar condições favoráveis à atuação de governos no uso das flexibilidades previstas em TRIPS. Tailândia e Brasil, por exemplo, adotaram, em 2006 e 2007, respectivamente, a licença compulsória do medicamentos antirretrovirais, propiciando uma redução de custos e a sustentabilidade do programa de acesso universal (36). Concomitantemente à atuação no contexto dos organismos internacionais, o Brasil estabeleceu um processo de cooperação bilateral com países africanos e latino-americanos, transferindo tecnologias e doando medicamentos para a implantação de programas de acesso aos antirretrovirais. Esses projetos tinham por objetivo demonstrar a factibilidade de os países de baixa e média renda desenvolverem, com sucesso, políticas de acesso a medicamentos. Pautavam-se no princípio da solidariedade e da cooperação horizontal. Um estudo de caso sobre a cooperação com Bolívia e Paraguai demonstrou a relevância e os desafios encontrados na implementação desses projetos (37).

O país impulsionou, a partir da Sessão Especial Geral das Nações Unidas, em 2003, a formação de uma rede internacional de cooperação tecnológica que, envolvendo países como China, Tailândia, Ucrânia, Nigéria e Rússia, tinha por objetivo diminuir a dependência dos países através do desenvolvimento de protocolos conjuntos de inovação e de transferência de tecnologia nas áreas de fármacos, vacinas e insumos de prevenção e do uso efetivo das flexibilidades previstas em TRIPS e na Declaração de Doha (38).

O Brasil também se destacou por suas políticas preventivas, que ganharam destaque no cenário internacional, por seu estilo marcado pela criatividade e pela tolerância social. De fato, o Brasil imprimiu em suas campanhas uma marca de ousadia que raramente é observada nos países latino-americanos, em outros países de baixa e média renda e mesmo em alguns países desenvolvidos. O caráter ousado e polêmico das campanhas preventivas brasileiras foi inaugurado com o cartaz "Transe numa Boa", produzido em 1985 pelo GAPA-SP $(22,31)$. O cartaz, dirigido principalmente à comunidade homossexual, chamava a atenção para a aids e proclamava o sexo seguro para evitar a infecção, empregando diversos termos usados nas cenas em que ocorre a prática sexual. A partir de então, as campanhas passaram a enfatizar o uso da camisinha como estratégia de saúde pública, abordando o tema a partir da erotização e do contexto das diversas práticas sexuais e relações afetivas.

A adoção de projetos de intervenção comunitária, desenvolvidos especialmente por organizações não governamentais, e a estabilização do número de novos casos da infecção, a partir dos anos 2000, contribuíram para que o Brasil fosse reconhecido mundialmente por sua resposta à epidemia de aids, consolidando o seu papel de liderança internacional. Esse fato certamente contribuiu para o fortalecimento da resposta brasileira dentro do próprio país.

\section{CONCLUSÃO}

O processo de abertura política, a reorganização dos movimentos sociais, a reforma do setor saúde e a atuação internacional permitiram que a resposta à epi- 
demia de aids no Brasil alcançasse os resultados positivos verificados nesses últimos 25 anos. Foi o processo de abertura política e de redemocratização que criou as condições necessárias para que o estado incorporasse as demandas sociais e as traduzisse em políticas de saúde desenhadas e planejadas em conformidade com as necessidades da população; o movimento da reforma sanitária e a reorganização do sistema de saúde brasileiro, nas décadas de 1970 e 1980, contribuíram para estabelecer os referenciais éticos e os princípios que sustentaram a política nacional para aids - equidade, universalidade e integralidade -, para promover uma intervenção precoce, respondendo aos desafios de diagnosticar e tratar pessoas socialmente marginalizadas e que, até então, não estavam inseridas nos serviços de saúde, como os travestis e os usuários de drogas, e para articular uma resposta interssetorial.

O ativismo da sociedade civil, por sua vez, conferiu urgência e manteve a resposta à epidemia de aids como uma das principais prioridades de saúde pública nesses 25 anos. Foi essencial, para tanto, o desenvolvimento de conceitos que permitiram a superação de abordagens normativas e frequentemente estigmatizantes, desenvolvidas no campo da saúde. Nesse contexto, a solidariedade, como matriz do ativismo, permitiu que a sociedade criasse um movimento para minimizar os impactos negativos da doença e promover o envolvimento de uma multiplicidade de pessoas e de instituições na luta contra a epidemia. É necessário ressaltar que, se a epidemia contribuiu para reafirmar a exclusão de segmentos sociais já marginalizados, foi a resposta à doença que permitiu que esses grupos se organizassem, alcançassem maior visibilidade social e ganhassem espaço nas políticas públicas. Entre esses avanços merece destaque o fortalecimento do movimento homossexual, das profissionais do sexo e de usuários de drogas. Esse trabalho procurou demonstrar que a sinergia entre os movimentos da reforma sanitária e de afirmação de identidades sociais, no contexto da abertura política, fundamentou a organização de uma resposta social que obteve êxito no controle da epidemia. A esses fatores se somou a atuação brasileira no cenário internacional, que teve o papel de garantir a sustentabilidade da resposta brasi- leira e de fortalecer os vínculos de solidariedade entre países do hemisfério sul.

Esse cenário é, sem dúvida, um ambiente favorável para a resposta nacional, mas os desafios para o efetivo controle da doença ainda são numerosos. Passados 25 anos, mais de 30 mil pessoas adoecem de aids e quase 15 mil morrem em decorrência da doença a cada ano no Brasil. As desigualdades regionais são gritantes e a velocidade de crescimento do número de novos casos é mais expressiva nas regiões Norte e Nordeste, entre mulheres e entre aqueles com menores condições sociais. Homossexuais, usuários de drogas, travestis, presidiários e profissionais do sexo enfrentam um risco significativamente maior de se infectar do que a população em geral. Os gastos com o controle da epidemia são elevados e tendem a aumentar, enquanto que permanece limitada a capacidade brasileira para racionalizar esses gastos. Isso exigirá da sociedade um esforço adicional e novas formas de atuação.

\section{SYNOPSIS}

\section{Response to AIDS in Brazil: contributions of social movements and the sanitary reform}

This paper briefly outlines how the political scenario and the mobilization of different actors have contributed to the construction of a public health policy in response to the AIDS epidemics in Brazil. Three factors are presented and discussed: the political context of the 1980s, characterized by redemocratization, growth of social movements, and consolidation of the Brazilian health care reform; the socio-cultural context of the 1970s and 1980s, characterized by achievement of individual freedom, which was key to the organization of the AIDS movement; and finally the actions carried out in the international scenario to support the sustainability of the Brazilian domestic policy and the reinforcement of a global response to face the epidemics in lower-middle income economies.

Key words: acquired immunodeficiency syndrome, historical article, health policy, non-governmental organizations, health care reform.

\section{REFERÊNCIAS}

1. Dourado I, Veras MASM, Barreira D, Brito AM. Tendências da epidemia de Aids no Brasil após a terapia anti-retroviral. Rev Saude Publica. 2006;40(supl): 9-17.

2. Boletim Epidemiológico - Aids. Ministério da Saúde. Secretaria de Vigilância da Saúde. Programa Nacional de DST/ Aids 2008;1(12-37).

3. Report on the global HIV/AIDS epidemic 2008. Genebra: UNAIDS; 2008. Disponível em: http://www.unaids.org/en/ KnowledgeCentre/HIVData/Global Report/2008/2008_Global_report.asp. Acessado em julho de 2009.
4. Sevalho G. A historical approach to social representations of health and disease. Cad Saude Publica. 1993;9(3):349-63.

5. Silveira AJT. A medicina e a influenza espanhola de 1918. Tempo. 2005;109(19): 91-105.

6. Okie S. Fighting HIV: lessons from Brazil. N Engl J Med. 2006;354(19):1977-81. Disponível em: http://content.nejm.org/ cgi/content/full/354/19/1977. Acessado em julho de 2009.

7. Parker R, Camargo Jr KR. Pobreza e HIV/AIDS: aspectos antropológicos e sociológicos. Cad Saude Publica. 2000;16 (sup1):S89-102.
8. Bastos FI, Szwarcwald CL. AIDS e pauperização: principais conceitos e evidências empíricas. Cad Saude Publica. 2000; 16(Sup1):S65-76.

9. Levi CG, Vitória MAA. Fighting against AIDS: the Brazilian experience. AIDS. 2002;16(18):2373-83

10. Escorel S. Reviravolta na saúde: origem e articulação do movimento sanitário. Rio de Janeiro: Fiocruz; 1999.

11. Mascarenhas RS. História da saúde pública no Estado de São Paulo. Rev Saude Publica. 1973;17(4):433-46.

12. Cordeiro H. O Instituto de Medicina Social e a luta pela reforma sanitária: con- 
tribuição à história do SUS. Physis. 2004; 14(2):343-62.

13. Nemes MIB. Ações programáticas em saúde: recuperação histórica de uma política de programação. Em: Schaiber LB, Nemes MIB, Mendes-Gonçalves RB, orgs. Programação em saúde hoje. São Paulo: Hucitec; 1990. Pp. 65-116.

14. Tanaka OY, Escobar EMA, Gimenez ASM, Camargo KG, Lelli CLS, Yoshida TM. Gerenciamento do setor saúde na década de 80, no Estado de São Paulo, Brasil. Rev Saude Publica. 1992;26(3):185-94.

15. Teixeira PR. Políticas públicas em aids. Em: Parker R, ed. Políticas, instituições e aids: enfrentando a epidemia no Brasil. Rio de Janeiro: ABIA; 1997. Pp 143-68.

16. Guerra MA. Política de controle da Aids da Secretaria da Saúde do Estado de São Paulo, no período de 1983-1992: a história contada por seus agentes [dissertaçãol. São Paulo: Faculdade de Medicina da Universidade de São Paulo; 1993.

17. Oliveira MLW, Mendes CM, Tardim RT, Cunha MD, Arruda A. A representação social da hanseníase, trinta anos após a substituição da terminologia lepra no Brasil. História, Ciência, Saúde-Manguinhos. 2003;10(supl 1):41-8.

18. Galvão J. Aids no Brasil: a agenda de construção de uma epidemia. Rio de Janeiro: Editora 34; 2000.

19. Laurindo da Silva L. Vivre avec le sida en phase avancée. Une étude de sociologie de la maladie. Paris: L'Harmattan; 1999.

20. Mac Rae E. A construção da igualdade: identidade sexual e política no Brasil da abertura. Campinas: Editora da Unicamp; 1990.

21. Conde MCF. O movimento homossexual brasileiro, sua trajetória e seu papel na ampliação do exercício da cidadania [dissertação]. Goiânia: Faculdade de Ciência Humanas e Filosofia, Universidade Federal de Goiás; 2004. Disponível em: http:/ / www.fchf.ufg.br/pos-sociologia/dissert/
Michele.pdf. Acessado em 27 de outubro de 2008.

22. Laurindo da Silva L (Dalva Teodorescu). Aids e homossexualidade em São Paulo [dissertação]. São Paulo: Pontifícia Universidade Católica de São Paulo; 1986.

23. Silva CLC. ONG/Aids, intervenções sociais e novos laços de solidariedade social. Cad Saude Publica. 1998;14(Supl 2): 129-39.

24. Galvão J. As respostas das organizações não governamentais brasileiras frente à epidemia de AIDS. Em: Parker R, ed. Políticas, instituições e Aids - enfrentando a epidemia no Brasil. Rio de Janeiro: Zahar/ABIA; 1997.

25. Parker R, ed. Solidariedade: a ABIA na virada do milênio. Rio de Janeiro: ABIA; 2001.

26. França MSJ. Respondendo o modelo para a divulgação científica: o caso aids na imprensa brasileira (1981-2001) [dissertação]. São Paulo: Pontifícia Universidade Católica; 2002.

27. Grangeiro A. O perfil socioeconômico dos casos de aids da cidade de São Paulo. Em: Parker R, Bastos C, Galvão J, Pedrosa JS, eds. A aids no Brasil (19821992). Rio de Janeiro: Relume-Dumará; 1994. Pp. 91-128.

28. Valle CG. Identidades, doença e organização social: um estudo das pessoas vivendo com HIV e aids. Horizontes Antropológicos. 2002;8(17):179-210.

29. Daniel H. Vida antes da morte. $20^{a}$ ed. Rio de Janeiro: ABIA, 1994.

30. Fasto Neto A. A morte em derrapagem. Os casos Corona e Cazuza no discurso da comunicação de massa. Rio de Janeiro: Fundo Editorial; 1989.

31. Lindner L, ed. ENONG - Encontro Nacional de ONG/AIDS: construção de sonhos e lutas. Curitiba: Grupo Dignidade; 2005

32. Galvão J. A política brasileira de distribuição e produção de medicamentos anti-retrovirais: privilégio ou um direito? Cad Saude Publica. 2002;18(1):213-9.

33. Parada AMM. A declaração da OMC sobre acordo TRIPS e saúde pública (Doha, 2001) - Um estudo de caso sobre a liderança brasileira em foros internacionais [dissertação]. Brasília: Universidade Nacional de Brasília; 2005.

34. WHO/UNAIDS. Towards universal access: scaling up priority HIV/AIDS interventions in the health sector: progress report 2008. Genebra: WHO/UNAIDS; 2008. Disponível em: http://www.who. int/hiv/pub/towards_universal_access _report_2008.pdf. Acessado em 31 de outubro de 2008.

35. Nemes MIB, Beaudoin J, Conway S, Kivumbi GW, Skjelmerud A, Vogel U. Evaluation of WHO's contribution to " 3 by 5": main report. Genebra: WHO; 2006

36. Grangeiro A, Teixeira P. Repercussões do acordo de propriedade intelectual no acesso a medicamentos. Em: Vilares F, ed. Propriedade intelectual: tensões entre o capital e sociedade. Rio de Janeiro: Paz e Terra; 2007. Pp. 115-39.

37. Pimenta C, Terto Jr V, Kamel L, Maksud I, Raxach JC, eds. Acesso a tratamento de Aids na Bolívia e Paraguai: cooperação internacional e mobilização social. Rio de Janeiro: ABIA; 2006. [Coleção Políticas Públicas].

38. Joint declaration between the Federal Republic of Nigeria, the Federative Republic of Brazil, the Kingdom Thailand, the People's Republic of China, the Republic of Ukraine and the Russian Federation on the scope of the against HIV/Aids. Bangkok, 2004. Disponível em: http:/ / www.aids.gov.br/main.asp? Team $=\% 7 B 57036654-8045-464 \mathrm{E}-845 \mathrm{~B}$ 6AD9A48712C0\%7D. Acessado em abril de 2008.

Manuscrito recebido em 9 de maio de 2008. Aceito em versão revisada em 6 de novembro de 2008 . 